\title{
Case Report \\ Reversibility of High-Grade Atrioventricular Block with Revascularization in Coronary Artery Disease without Infarction: A Literature Review
}

\author{
Rhanderson Cardoso, Carlos E. Alfonso, and James O. Coffey \\ Miller School of Medicine, University of Miami, Miami, FL 33136, USA \\ Correspondence should be addressed to James O. Coffey; jamesodellcoffey@gmail.com
}

Received 2 November 2015; Accepted 10 January 2016

Academic Editor: Konstantinos P. Letsas

Copyright (C) 2016 Rhanderson Cardoso et al. This is an open access article distributed under the Creative Commons Attribution License, which permits unrestricted use, distribution, and reproduction in any medium, provided the original work is properly cited.

Complete atrioventricular (AV) block is known to be reversible in some cases of acute inferior wall myocardial infarction (MI). The reversibility of high-grade AV block in non-MI coronary artery disease (CAD), however, is rarely described in the literature. Herein we perform a literature review to assess what is known about the reversibility of high-grade AV block after right coronary artery revascularization in CAD patients who present without an acute MI. To illustrate this phenomenon we describe a case of 2:1 AV block associated with unstable angina, in which revascularization resulted in immediate and durable restoration of $1: 1 \mathrm{AV}$ conduction, thereby obviating the need for permanent pacemaker implantation. The literature review suggests two possible explanations: a vagally mediated response or a mechanism dependent on conduction system ischemia. Due to the limited understanding of AV block reversibility following revascularization in non-acute MI presentations, it remains difficult to reliably predict which patients presenting with high-grade AV block in the absence of MI may have the potential to avoid permanent pacemaker implantation via coronary revascularization. We thus offer this review as a potential starting point for the approach to such patients.

\section{Introduction}

Permanent pacing is the routine treatment for irreversible third-degree and advanced second-degree atrioventricular (AV) block [1, 2]. Although necessary and effective in most patients with such conditions, the implantation of a permanent pacemaker is costly $[3,4]$ and is associated with significant potential acute complications, including but not limited to infection [5], bleeding [6], hematoma [2], hemothorax [7], lead dislodgement [8], and atrial $[9,10]$ or ventricular $[9,11]$ rupture. Moreover, pacemaker leads over time are subject to fracture, insulation break, or recall, which may require lead extraction, a potentially high-risk procedure $[12,13]$. It is therefore desirable from both societal [14] and individual [15] patient points of view to thoroughly rule out all reversible causes of bradyarrhythmia before commitment to a permanent device [2]. Reversible causes of high-grade AV block include hypothyroidism [16], hyperthyroidism [17], lymphoma [18], herbal medications [19], chemotherapeutic agents [20], Lyme disease [21], viral myocarditis [22], apical ballooning syndrome [23], and negative chronotropic agents [24].

Acute myocardial infarction (MI), particularly with injury to the inferior wall, is also a well-described cause of reversible AV block [25-27]. Potential reversibility of highgrade AV block in coronary artery disease (CAD) patients without an acute MI, in contrast, is a relatively unexplored concept. Herein, we present a literature review prompted by a case of unexpected postrevascularization reversal of symptomatic AV block.

\section{Illustrative Case Description}

An 85-year-old man with a history of ischemic cardiomyopathy and baseline ejection fraction of $40 \%$ following an inferior wall MI in 1996 presented with approximately one week of lightheadedness and chest pain at rest. Previously, his symptoms of chronic stable angina were well controlled 


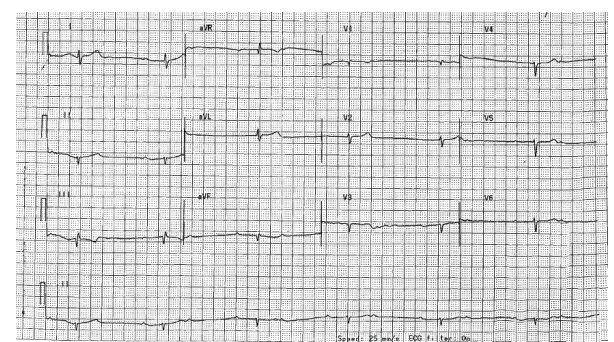

Figure 1: Two : one atrioventricular block in a patient with unstable angina prior to revascularization.

with isosorbide mononitrate. An electrocardiogram was performed, revealing 2:1 AV block with a ventricular rate of 37 beats per minute (Figure 1). The patient had no prior history of conduction system abnormality. Common causes of reversible $\mathrm{AV}$ block were excluded, and the patient was admitted in anticipation of permanent pacemaker implantation. Cardiac biomarkers were negative. Cardiac monitoring continued to show 2:1 and occasionally higher-grade AV block.

Given the history of ischemic cardiomyopathy and symptoms consistent with unstable angina, a decision was made to proceed with left heart catheterization before pacemaker implantation. Coronary angiography revealed a dominant right coronary artery (RCA) with $80 \%$ ostial stenosis (Figure 2(a)). A drug-eluting stent was successfully deployed to the ostial RCA lesion with an outstanding angiographic result (Figure 2(b)). Upon revascularization, the patient immediately reverted to 1:1 AV conduction (Figure 3) and has remained in normal sinus rhythm with mild first-degree AV block since then. The lightheadedness and fatigue have entirely resolved. Permanent pacemaker implantation was avoided.

\section{Theoretical Mechanisms of AV Block Reversibility in Coronary Artery Disease}

The noteworthy finding in this case is the complete resolution of symptomatic high-grade AV block upon revascularization of the RCA. Review of the literature reveals two possible mechanisms for the presence of clinically significant AV block in patients without MI who experience restoration of normal AV conduction following coronary revascularization. These mechanisms are vagally mediated heart block and ischemia-driven conduction delay.

3.1. Vagal Hypothesis. Vagally mediated bradyarrhythmia is well documented in patients with myocardial ischemia or injury. Ischemic-mediated mechanical stretch and chemical substances stimulate receptors located in the inferior and posterior left ventricular walls [28]. These receptors lead to activation of nonmyelinated afferent C-fibers from the vagus nerve, which in turn result in increased vagal tone and bradyarrhythmia $[28,29]$. This mechanism is known as the Bezold-Jarisch reflex. One case report discusses a patient with non-ST elevation MI who developed complete heart block in the setting of a $90 \%$ stenosis of the RCA acute marginal branch. The AV block resolved after balloon angioplasty of this lesion. Because the acute marginal branch does not supply the AV node, the mechanism for third-degree AV block was attributed to the Bezold-Jarisch reflex triggered by inferior wall ischemia [29].

Patients with CAD are especially susceptible to vagal stimulation, as demonstrated by the frequency of carotid sinus hypersensitivity in this population, as well as by the correlation of carotid hypersensitivity with the severity of CAD [30-32]. Jick and Linenthal, for example, reported a case of 2:1 AV block in an 85-year-old man with two previous myocardial infarctions and ischemic cardiomyopathy. In a time before percutaneous coronary intervention was available, they observed complete reversal of the 2:1 AV block to $1: 1 \mathrm{AV}$ conduction with atropine administration, as well as progression to complete heart block with carotid sinus massage, phenomena consistent with a vagal etiology of the conduction system disease [33]. Furthermore, coronary revascularization has been shown to attenuate postexercise heart rate decay in patients with RCA lesions, which suggests decreased vagal activity following reperfusion in inferior wall ischemia [34].

Although these descriptions confirm biologic plausibility, whether the decreased cardiac sensitivity to vagal stimuli after revascularization can fully reverse $2: 1 \mathrm{AV}$ block and avoid further episodes of high-grade AV block is difficult to prove and appears to be a rare phenomenon. Moreover, if the heart block was solely mediated by increased vagal tone, one would expect to see episodes of intermittent AV block during times of high vagal tone, despite revascularization.

3.2. Ischemia Hypothesis. AV conduction defects that resolve with revascularization may occur as a direct result of ischemia, a circumstance more consistent with complete postrevascularization restoration of $1: 1 \mathrm{AV}$ conduction, such as that observed in the case above. The AV node blood supply is provided by the AV nodal branch, which most commonly arises from the RCA [35], although it can rarely be a branch of the circumflex artery in patients with left coronary artery dominance [36-38]. Meanwhile, infranodal conduction system structures are supplied almost entirely by the septal perforator branches of the LAD artery, with variable dual supply provided by either the RCA or left circumflex artery [38-41]. Decreased flow to the septal branches or RCA is therefore associated with a variety of conduction disturbances [42, 43]. Importantly, the presence of high-grade AV block is associated with a 4-fold and 3-fold increased risk of in-hospital mortality for anterior and inferior wall acute infarctions, respectively [44]. Further, the presence of third-degree AV block in inferior MI has also been associated with an increased incidence of sustained hypotension and ventricular tachyarrhythmia [45].

In acute inferior wall MI, where the RCA is often the culprit, high-grade AV block has been described in up to $17 \%$ of cases [26]. Most of these cases are transient and resolve either spontaneously or with revascularization, whereas approximately $9 \%$ will ultimately require a permanent pacemaker, implicating permanent damage to $\mathrm{AV}$ conduction tissue prior to or due to lack of revascularization 


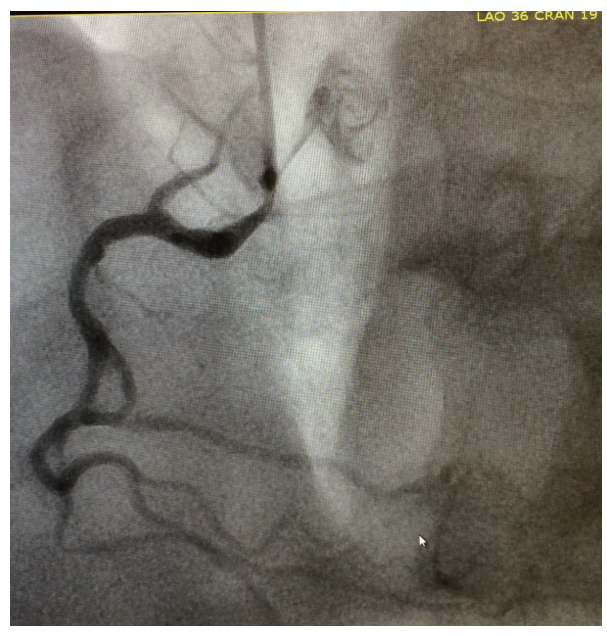

(a)

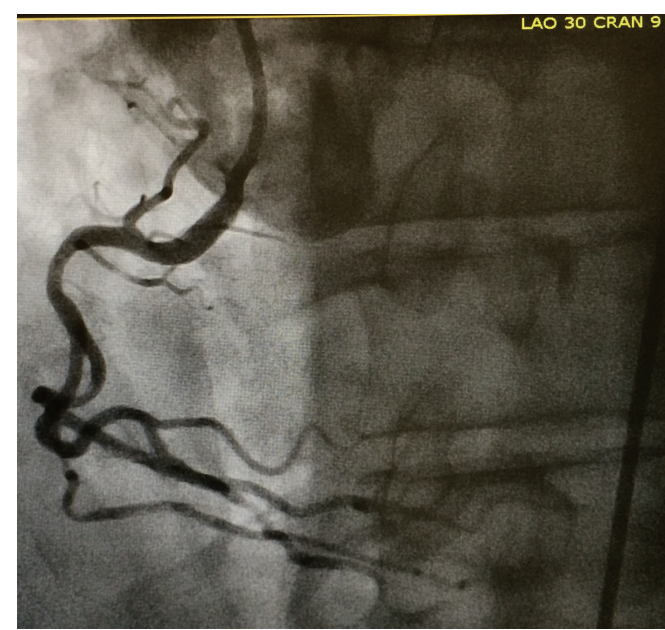

(b)

FiguRE 2: (a) Angiography revealed an $80 \%$ ostial stenosis in the right coronary artery; (b) right coronary artery after successful deployment of drug-eluting stent to ostial lesion.

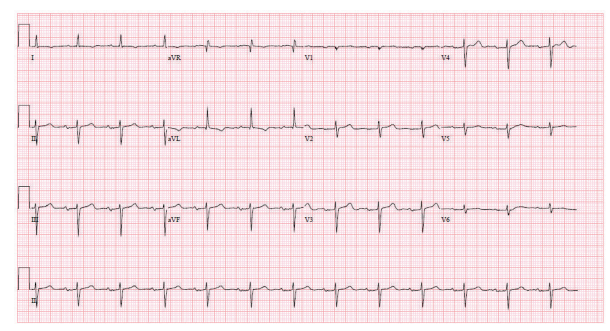

FIGURE 3: Resolution of $2: 1 \mathrm{AV}$ block after revascularization; residual 1st-degree AV block (PR $220 \mathrm{~ms}$ ).

[46, 47]. The 2008 ACC/AHA/HRS Guidelines for DeviceBased Therapy acknowledge that, in cases of third-degree AV block complicating inferior wall MI, permanent pacing should be reserved for patients in whom the block does not resolve with revascularization [1]. The possibility of transient AV block secondary to myocardial ischemia in patients without MI is not discussed in current practice guidelines [1].

3.3. AV Block Reversibility in Non-Myocardial Infarction Presentations. In patients with CAD presenting without acute $\mathrm{MI}$, the reversibility of high-grade AV block and the avoidance of pacemaker implantation via revascularization are infrequently described in the literature. In a single-center retrospective study evaluating the reversibility of AV block in patients with CAD, Hwang et al. assessed 188 patients with high-grade AV block for the presence of concomitant CAD. Fifty-eight $(30.8 \%)$ individuals were found to have CAD, distributed as follows: stable angina, 41; acute MI, 15; and unstable angina, 2. As expected, AV block was reversible with revascularization in 13 of the 15 patients presenting with acute MI. The culprit lesion was located in the RCA in 14 of the 15 acute MI patients. Conversely, only 1 of the 43 patients $(2.3 \%)$ with stable angina and none of the 2 patients with unstable angina reverted to $1: 1 \mathrm{AV}$ conduction after revascularization, despite the fact that roughly $60 \%(26 / 43)$ of these patients also had significant RCA lesions [48].

Yesil et al. studied 53 pacemaker patients with complete heart block and significant $\mathrm{CAD}$, defined by the presence of a coronary lesion with greater than $70 \%$ stenosis. In this study, patients with acute coronary syndrome were excluded. After a mean follow-up of $36 \pm 6$ months, third-degree AV block persisted in 13/16 (81\%) patients treated medically and in $27 / 37(73 \%)$ of the revascularized patients. Despite most of the lesions being in the RCA, the difference was not significant, leading the authors to conclude that, in the absence of acute $\mathrm{MI}$, coronary revascularization has minimal impact on regaining normal AV function in patients with concomitant third-degree AV block and CAD [49].

The remaining published assessments of AV block in CAD patients without MI are smaller case series. Omeroglu et al., for example, reported a series of 8 patients who presented with new-onset complete AV block and severe CAD requiring coronary artery bypass grafting. Revascularization was performed on the same admission, but none of the patients had resolution of complete AV block in a followup of $10 \pm 1.07$ days [50]. Narin et al. reported two cases of complete heart block in patients with unstable angina that required $\mathrm{CABG}$. When AV block in one of the patients remained on postoperative day 15 , he received a permanent pacemaker. The other patient, however, reverted to $1: 1 \mathrm{AV}$ conduction immediately after surgical revascularization, and the absence of significant AV block remained at a follow-up of 27.7 months [51]. Such an outcome, we believe, is likely analogous to the fortuitous clinical course experienced by the patient we describe above.

\section{Conclusion}

In summary, while new-onset high-grade AV block in the setting of CAD is less likely to be reversible in patients without acute MI, there are patients in whom revascularization leads 
to immediate and durable resolution of $1: 1 \mathrm{AV}$ conduction. Examples of this phenomenon include the case illustration above as well as anecdotal cases in the literature. This clinical course is fairly unusual and the mechanism responsible is uncertain. Possible mechanisms include vagal mediation and, more likely, ischemia. The majority of published data suggest that high-grade AV block is usually not reversible with revascularization in patients who have CAD and do not present with an acute MI. The rare case such as the one we describe above is a fortunate but currently unpredictable exception to the rule that such patients will require pacemaker implantation. Nevertheless, in light of the potential negative impacts of permanent pacemakers, it may be prudent to observe postrevascularization conduction before committing patients to device implantation.

\section{Conflict of Interests}

The authors declare that there is no conflict of interests regarding the publication of this paper.

\section{Authors' Contribution}

All authors participated in concept/design, literature review, drafting of the paper, critical revision of the paper, and final approval of the paper submitted.

\section{References}

[1] A. E. Epstein, J. P. DiMarco, K. A. Ellenbogen et al., "ACC/AHA/ HRS 2008 guidelines for device-based therapy of cardiac rhythm abnormalities: a report of the American College of Cardiology/American Heart Association Task Force on Practice Guidelines: developed in collaboration with the American Association for Thoracic Surgery and Society of Thoracic Surgeons," Circulation, vol. 117, pp. e350-e408, 2008.

[2] M. Brignole, A. Auricchio, G. Baron-Esquivias et al., "2013 ESC guidelines on cardiac pacing and cardiac resynchronization therapy: the Task Force on cardiac pacing and resynchronization therapy of the European Society of Cardiology (ESC)," Europace, vol. 15, pp. 1070-1118, 2013.

[3] E. Castelnuovo, K. Stein, M. Pitt, R. Garside, and E. Payne, "The effectiveness and cost-effectiveness of dual-chamber pacemakers compared with single-chamber pacemakers for bradycardia due to atrioventricular block or sick sinus syndrome: systematic review and economic evaluation," Health Technology Assessment, vol. 9, pp. 1-246, 2005.

[4] F. Osman, S. Krishnamoorthy, A. Nadir, P. Mullin, A. MorleyDavies, and J. Creamer, "Safety and cost-effectiveness of same day permanent pacemaker implantation," The American Journal of Cardiology, vol. 106, no. 3, pp. 383-385, 2010.

[5] J. B. Johansen, O. D. Jørgensen, M. Møller, P. Arnsbo, P. T. Mortensen, and J. C. Nielsen, "Infection after pacemaker implantation: infection rates and risk factors associated with infection in a population-based cohort study of 46299 consecutive patients," European Heart Journal, vol. 32, no. 8, pp. 991-998, 2011.

[6] C. Tompkins, A. Cheng, D. Dalal et al., "Dual antiplatelet therapy and heparin 'bridging' significantly increase the risk of bleeding complications after pacemaker or implantable cardioverter-defibrillator device implantation," Journal of the American College of Cardiology, vol. 55, no. 21, pp. 2376-2382, 2010.

[7] G. B. Forleo, J. Zeitani, T. Perretta et al., "Acute left hemothorax as a late complication of an active-fixation pacemaker lead," Annals of Thoracic Surgery, vol. 95, no. 3, pp. 1081-1084, 2013.

[8] A. Bashir, N. Noroozian, W. Bradlow, and H. Marshall, "Malposition of pacing lead into the left ventricle: a rare complication of pacemaker insertion," BMJ Case Reports, 2014.

[9] J. Piekarz, J. Lelakowski, A. Rydlewska, and J. Majewski, "Heart perforation in patients with permanent cardiac pacing-pilot personal observations," Archives of Medical Science, vol. 8, no. 1, pp. 70-74, 2012.

[10] A. J. Trigano and T. Caus, "Lead explantation late after atrial perforation," Pacing and Clinical Electrophysiology, vol. 19, no. 8, pp. 1268-1269, 1996.

[11] F. Migliore, A. Zorzi, E. Bertaglia et al., "Incidence, management, and prevention of right ventricular perforation by pacemaker and implantable cardioverter defibrillator leads," PACE, vol. 37, no. 12, pp. 1602-1609, 2014.

[12] E. Buch, N. G. Boyle, and P. H. Belott, "Pacemaker and defibrillator lead extraction," Circulation, vol. 123, no. 11, pp. e378-e380, 2011.

[13] B. L. Wilkoff, C. J. Love, C. L. Byrd et al., "Transvenous lead extraction: Heart Rhythm Society expert consensus on facilities, training, indications, and patient management: this document was endorsed by the American Heart Association (AHA)," Heart Rhythm, vol. 6, no. 7, pp. 1085-1104, 2009.

[14] A. A. Choby and A. M. Clark, "What costs matter? Rethinking social costs of new device technologies," Europace, vol. 15, no. 11, pp. 1538-1539, 2013.

[15] M. A. Wood and K. A. Ellenbogen, "Cardiology patient pages. Cardiac pacemakers from the patient's perspective," Circulation, vol. 105, no. 18, pp. 2136-2138, 2002.

[16] J. B. Singh, O. E. Starobin, R. L. Guerrant, and E. K. Manders, "Reversible atrioventricular block in myxedema," Chest, vol. 63, no. 4, pp. 582-585, 1973.

[17] R. H. Miller, F. H. Corcoran, and W. P. Baker, "Second and third degree atrioventricular block with Graves' disease: a case report and review of the literature," Pacing and Clinical Electrophysiology, vol. 3, no. 6, pp. 702-711, 1980.

[18] R. K. Crisel, B. P. Knight, and S. S. Kim, "Reversible, complete atrioventricular block caused by primary cardiac lymphoma in a nonimmunocompromised patient," Journal of Cardiovascular Electrophysiology, vol. 23, no. 12, pp. 1386-1389, 2012.

[19] S. Guha, B. Dawn, G. Dutta, T. Chakraborty, and S. Pain, "Bradycardia, reversible panconduction defeat and syncope following self-medication with a homeopathic medicine," Cardiology, vol. 91, no. 4, pp. 268-271, 1999.

[20] C.-H. Huang, W.-J. Chen, C.-C. Wu, Y.-C. Chen, and Y.-T. Lee, "Complete atrioventricular block after arsenic trioxide treatment in an acute promyelocytic leukemic patient," Pacing and Clinical Electrophysiology, vol. 22, no. 6, pp. 965-967, 1999.

[21] I. S. Bhattacharya, M. Dweck, and M. Francis, "Lyme carditis: a reversible cause of complete atrioventricular block," Journal of the Royal College of Physicians of Edinburgh, vol. 40, no. 2, pp. 121-122, 2010. 
[22] T. H. Yu, G. F. Guo, M. C. Chen, and C. H. Yang, "Reversible infra-Hisian atrioventricular block in acute myocarditis," Chang Gung Medical Journal, vol. 24, no. 10, pp. 651-656, 2001.

[23] H. M. Nef, H. Möllmann, J. Sperzel et al., "Temporary thirddegree atrioventricular block in a case of apical ballooning syndrome," International Journal of Cardiology, vol. 113, no. 2, pp. E33-E35, 2006.

[24] D. Osmonov, I. Erdinler, K. S. Ozcan et al., "Management of patients with drug-induced atrioventricular block," Pacing and Clinical Electrophysiology, vol. 35, no. 7, pp. 804-810, 2012.

[25] M. C. Gupta, M. M. Singh, P. K. Wahal, M. P. Mehrotra, and S. K. Gupta, "Complete heart block complicating acute myocardial infarction," Angiology, vol. 29, no. 10, pp. 749-757, 1978.

[26] A. C. Tans, K. I. Lie, and D. Durrer, "Clinical setting and prognostic significance of high degree atrioventricular block in acute inferior myocardial infarction: a study of 144 patients," American Heart Journal, vol. 99, no. 1, pp. 4-8, 1980.

[27] P. Nicod, E. Gilpin, H. Dittrich, R. Polikar, H. Henning, and J. Ross Jr., "Long-term outcome in patients with inferior myocardial infarction and complete atrioventricular block," Journal of the American College of Cardiology, vol. 12, no. 3, pp. 589-594, 1988.

[28] J. A. Chiladakis, N. Patsouras, and A. S. Manolis, "The BezoldJarisch reflex in acute inferior myocardial infarction: clinical and sympathovagal spectral correlates," Clinical Cardiology, vol. 26, no. 7, pp. 323-328, 2003.

[29] O. Bolorunduro, R. N. Khouzam, and D. Dishmon, "Resolution of complete heart block after revascularization of acute marginal branch of the right coronary artery," Turk Kardiyoloji Dernegi Arsivi, vol. 42, no. 7, pp. 667-670, 2014.

[30] C. P. Tsioufis, I. E. Kallikazaros, K. P. Toutouzas, C. I. Stefanadis, and P. K. Toutouzas, "Exaggerated carotid sinus massage responses are related to severe coronary artery disease in patients being evaluated for chest pain," Clinical Cardiology, vol. 25, no. 4, pp. 161-166, 2002.

[31] I. Kallikazaros, C. Stratos, C. Tsioufis et al., "Carotid sinus hypersensitivity in patients undergoing coronary arteriography: relation with the severity of carotid atherosclerosis and the extent of coronary artery disease," Journal of Cardiovascular Electrophysiology, vol. 8, no. 11, pp. 1218-1228, 1997.

[32] K. A. Brown, J. D. Maloney, H. C. Smith, G. O. Haritzler, and D. M. Ilstrup, "Carotid sinus reflex in patients undergoing coronary angiography: relationship of degree and location of coronary artery disease to response to carotid sinus massage," Circulation, vol. 62, no. 4, pp. 697-703, 1980.

[33] H. Jick and A. J. Linenthal, "Reversible Wenckebach type atrioventricular block associated with severe coronary artery disease," Circulation, vol. 20, no. 2, pp. 262-266, 1959.

[34] N. Tahara, H. Takaki, A. Taguchi et al., "Pronounced HR variability after exercise in inferior ischemia: evidence that the cardioinhibitory vagal reflex is invoked by exercise-induced inferior ischemia," The American Journal of Physiology-Heart and Circulatory Physiology, vol. 288, no. 3, pp. H1179-H1185, 2005.

[35] S. H. El-Maasarany, E. E. B. Elazab, S. Jensen, and M. Y. Henein, "A-V nodal artery anatomy and relations to the posterior septal space and its contents," International Journal of Cardiology, vol. 141, no. 1, pp. 92-98, 2010.
[36] J.-L. Lin, S. K. S. Huang, L.-P. Lai et al., "Distal end of the atrioventricular nodal artery predicts the risk of atrioventricular block during slow pathway catheter ablation of atrioventricular nodal re-entrant tachycardia," Heart, vol. 83, no. 5, pp. 543-550, 2000 .

[37] M. C. Hutchinson, "A study of the artrial arteries in man," Journal of Anatomy, vol. 125, pp. 39-54, 1978.

[38] P. J. Zimetbaum and M. E. Josephson, "Use of the electrocardiogram in acute myocardial infarction," The New England Journal of Medicine, vol. 348, no. 10, pp. 933-940, 2003.

[39] D. Harpaz, S. Behar, S. Gottlieb, V. Boyko, Y. Kishon, and M. Eldar, "Complete atrioventricular block complicating acute myocardial infarction in the thrombolytic era," Journal of the American College of Cardiology, vol. 34, no. 6, pp. 1721-1728, 1999.

[40] R. M. Norris, "Heart block in posterior and anterior myocardial infarction," British Heart Journal, vol. 31, no. 3, pp. 352-356, 1969.

[41] L. G. van der Hauwaert, R. Stroobandt, and L. Verhaeghe, "Arterial blood supply of the atrioventricular node and main bundle," British Heart Journal, vol. 34, no. 10, pp. 1045-1051, 1972.

[42] S. Wei, L. Zhong, S. Chen, and X. Li, “The status of coronary artery lesions in patients with conduction disturbance," Journal of Cardiovascular Medicine, vol. 12, no. 10, pp. 709-713, 2011.

[43] M. Yesil, E. Arikan, N. Postaci, S. Bayata, and R. Yilmaz, "Locations of coronary artery lesions in patients with severe conduction disturbance," International Heart Journal, vol. 49, no. 5, pp. 525-531, 2008.

[44] K. McDonald, J. J. O’Sullivan, R. M. Conroy, K. Robinson, and R. Mulcahy, "Heart block as a predictor of in-hospital death in both acute inferior and acute anterior myocardial infarction," Quarterly Journal of Medicine, vol. 74, no. 275, pp. 277-282, 1990.

[45] P. Clemmensen, E. R. Bates, R. M. Califf et al., "Complete atrioventricular block complicating inferior wall acute myocardial infarction treated with reperfusion therapy. TAMI Study Group," American Journal of Cardiology, vol. 67, no. 4, pp. 225230, 1991.

[46] C. Giglioli, M. Margheri, S. Valente et al., "Timing, setting and incidence of cardiovascular complications in patients with acute myocardial infarction submitted to primary percutaneous coronary intervention," Canadian Journal of Cardiology, vol. 22, no. 12, pp. 1047-1052, 2006.

[47] U. J. O. Gang, A. Hvelplund, S. Pedersen et al., "Highdegree atrioventricular block complicating ST-segment elevation myocardial infarction in the era of primary percutaneous coronary intervention," Europace, vol. 14, no. 11, pp. 1639-1645, 2012.

[48] I.-C. Hwang, W.-W. Seo, I.-Y. Oh, E.-K. Choi, and S. Oh, "Reversibility of atrioventricular block according to coronary artery disease: results of a retrospective study," Korean Circulation Journal, vol. 42, no. 12, pp. 816-822, 2012.

[49] M. Yesil, S. Bayata, E. Arikan, R. Yilmaz, and N. Postaci, "Should we revascularize before implanting a pacemaker?" Clinical Cardiology, vol. 31, no. 10, pp. 498-501, 2008.

[50] S. N. Omeroglu, H. Ardal, H. B. Erdogan et al., "Can revascularization restore sinus rhythm in patients with acute onset 
atrioventricular block?” Journal of Cardiac Surgery, vol. 20, no. 2, pp. 136-141, 2005.

[51] C. Narin, A. Ozkara, A. Soylu et al., "The effect of coronary revascularization on new-onset complete atrioventricular block due to acute coronary syndrome," Heart Surgery Forum, vol. 12, no. 1, pp. E30-E34, 2009. 


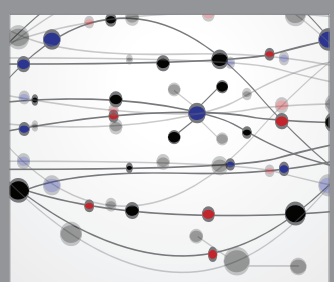

The Scientific World Journal
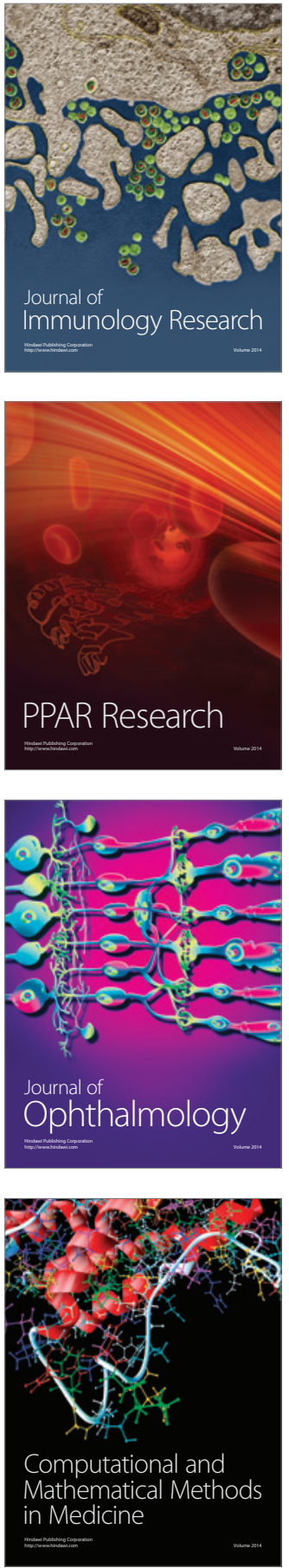

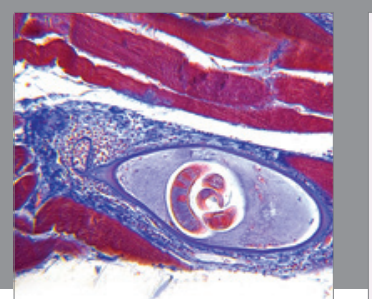

Gastroenterology Research and Practice

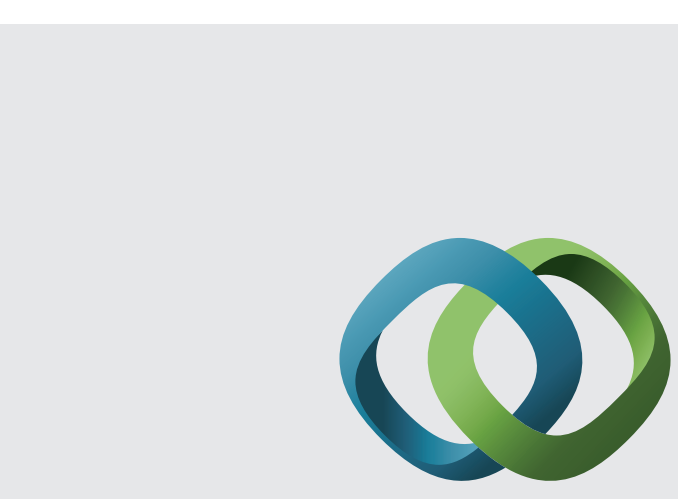

\section{Hindawi}

Submit your manuscripts at

http://www.hindawi.com
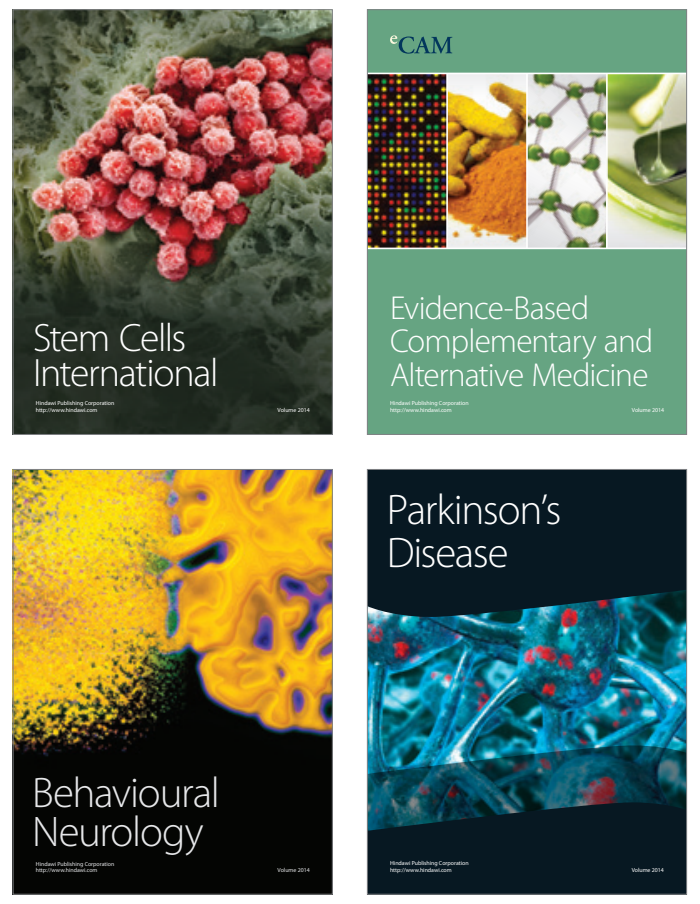
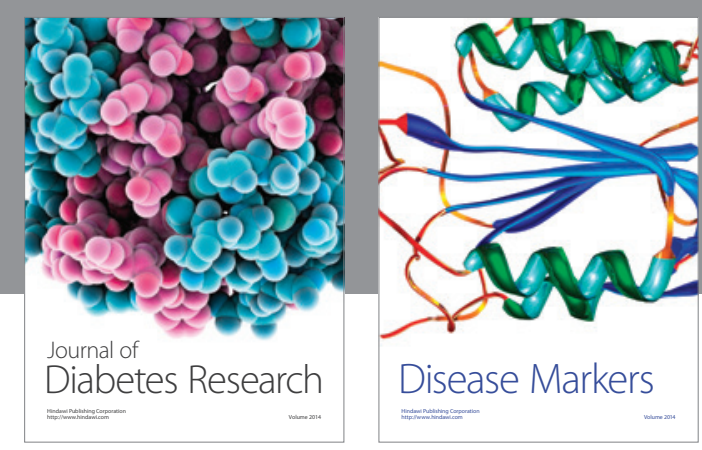

Disease Markers
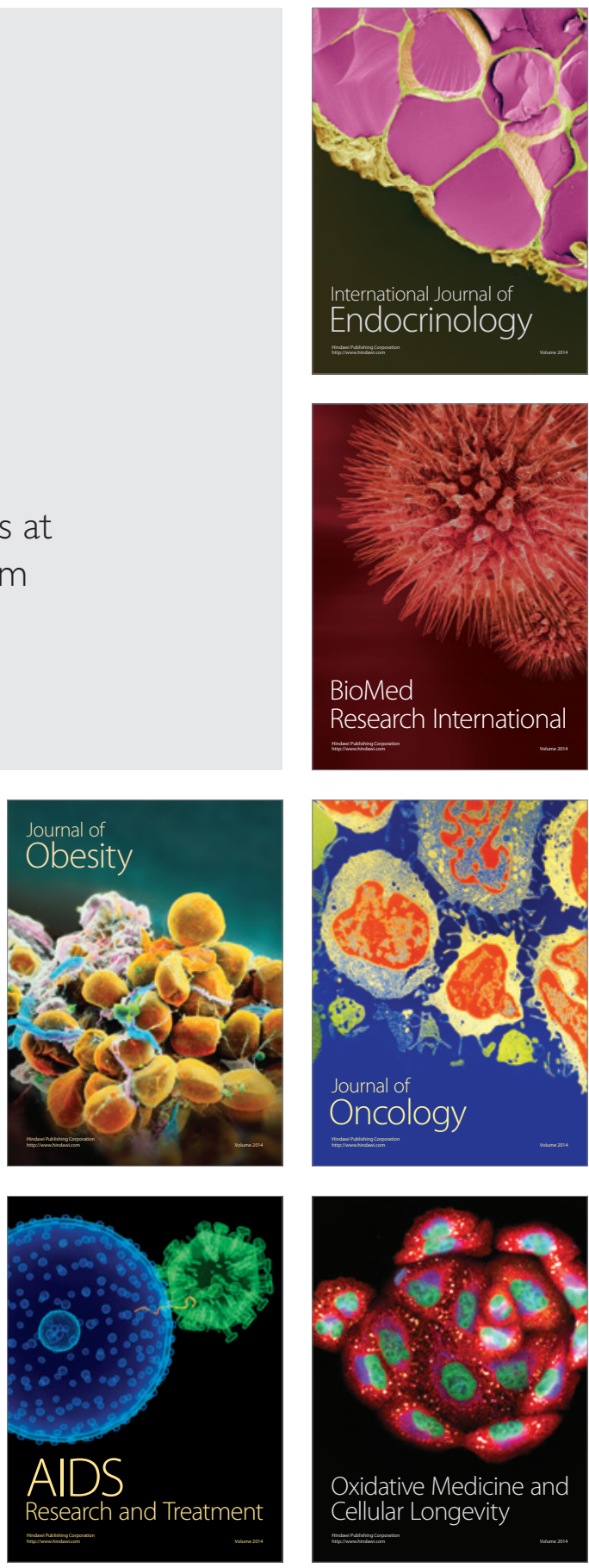